\title{
The Fretful Euro Disneyland
}

\author{
Wenhe Yue \\ School of Management, Shenyang Jianzhu University \\ Shenyang 110168, China \\ E-mail: bobo1012@sina.com
}

\begin{abstract}
Euro Disneyland a theme park comprised of an updated, state of the art Disney's Magic Kingdom, is a subsidiary of the Walt Disney Company located outside Paris, France, and has experienced numerous complications from its inception. This article introduces the fretful of Euro Disney, analyzes the reasons why it goes to wrong and give the recommendation to overcome the rattrap.
\end{abstract}

Keywords: Euro Disneyland, Cultural differences, Management hubris

\section{Introduction}

Many companies throughout the United States and beyond are resorting to developing their business abroad. The Walt Disney Company was one of the American organizations to expand on foreign soil. Its first foreign venture Tokyo Disneyland proved to be so successful that the decision was made to further expand abroad. This next foreign expansion experience, named Euro Disneyland all hopes were high, with Michael Eisner, the chairperson of Walt Disney promising to make Euro Disney the "most lavish project that Disney had ever built". He had an obsession with maintaining Disney's high reputation, as Disney had already seen the success of California and Florida Disneyland. While Euro Disney did not prove to be the successful venture that had been anticipated by its creators.

Euro Disneyland a theme park comprised of an updated, state of the art Disney's Magic Kingdom, is a subsidiary of the Walt Disney Company located outside Paris, France, and has experienced numerous complications from its inception. Because the Walt Disney Company executives were determined to adhere to American philosophies, they did not thoroughly investigate all aspects of the European environment.

As a company planning on expanding abroad, it is helpful to study the history of companies, which previously have developed in other countries. For example, studying the Walt Disney Company's venture into France will allow other companies to learn from the Walt Disney Company's experiences. Recognizing, understanding and avoiding their mistakes will allow a company entering a new country increased opportunity to succeed. Reviewing the Euro Disneyland venture from the site research investigation to the present day operation will be beneficial to a company considering expansion abroad.

\section{Where Euro Disney went wrong}

Disney made a number of mistakes in relation to planning for Euro Disney. While there was extensive research and planning, Disney may have disregarded some of the most important cultural aspects, including environmental and location factors, labor laws, competition, financing, cultural differences and management hubris.

\subsection{Environmental and location factors}

While over 200 locations in Europe were examined before selecting the outside of Paris, Disney relied on Europe's biggest appeal for tourism. It was viewed that millions of people could easily access Euro Disney, as the French government was spending hundreds of millions of dollars to provide infrastructure such as railroad so people could access the theme park. The opening to the Channel Tunnel in 1993 would make the trip from London to Euro Disney approximately three hours and ten minutes. However, the location was on the east Paris, not the west, despite the advice of the French. The French advised that if it were placed on the west, there would be no long-term population in the east.

Erisner also considered the weather impacts and because France has colder weather than California and Florida, waiting areas and moving side walks would be covered, protecting visitors from wind and rain. Because there is only six months of the year that is pleasant, visitors were not encouraged on a year round basis. Although accommodation were made, in fact that off-season visit had to be heavily discounted had promoted to group to get even reasonable attendance still represented a major problem that needed to be corrected. Whether through pricing charges or development of other attraction or other marketing and promotional vehicles, attendance in the off-park months had to be increased. 


\subsection{Cultural differences}

The firm's senior marketing strategist presented the second part of the report, which focused on culture and marketing difference between U.S and European markets. The first phase of the analysis had uncovered a number of obvious problems some of which had already been rectified. The purpose in identifying these problems, the consultant said, was to be able to sensitive and identify other possibly more subtle and marketing problems. Although European public acceptance of the theme park itself has not been a problem for Euro Disneyland there has been a different type of cultural clash. Most Europeans believe there is cultural imperialism. Europeans have not taken to the "...brash, frequently insensitive and often overbearing style of Mickey's American corporate parent". Disney executives' contentious attitudes exacerbated the difficulties it encountered by alienating people with whom it needed to work. "Its answer to doubts or suggestions invariably was: Do as we say, because we know best".

There were various errors made in the operations of Euro Disneyland, which affected the French culture. An example if this is the Walt Disney Company's policy of serving no alcohol in its parks in California, Florida, and Tokyo, which it extended to France. However by implementing this American strategy, it caused astonishment and rebellion in France where a glass of wine for lunch is a given. It failed to recognize that alcohol is viewed as a regular beverage with meals and a part of daily life. After much consideration, in May 1993, the Walt Disney Company changed its policy and allowed wine and beer in the Euro Disneyland theme park.

Another failure is the Walt Disney Company's misunderstanding European breakfast norms. The initial thinking was that Europeans did not generally eat a big breakfast and, as result restaurant were planned to seat only a small number of breakfast guests. This proved incorrect with large numbers of people showing up for substantial breakfasts. Disney was told Europeans did not eat sit-down breakfasts. This resulted in Disney downsizing their restaurants before Euro Disneyland opened. Once it opened the restaurants were bombarded with breakfast eaters.

In much the same vein, the Walt Disney Company had difficulty realizing that the Europeans were accustomed to eat at a set time every day. Where Americans are content to wander around the parks with lunch in their hands, a large majority of the European guests would converge on the restaurants at 12:30 p.m. expecting to be seated for a leisurely lunch. This caused the lines to be very long. To complicate matters further, once the Europeans reached the front of the line they were told they could not have wine or beer with their lunch. Thus, the Europeans did not have a positive "Disney experience" while eating their meals. In addition, it was difficult for Euro Disneyland's managers to staff for these one or two hour "rush hours."

The forth example of a cultural error is the Europeans approach to vacation time. Disney also thought that because the French and Germans typically have five weeks' vacation, compared to American, who on average has two-three weeks, it would be an advantage to them. The Europeans prefer a few longer holidays rather than several short breaks. Attendance at the Euro Disney was also seasonal; with parents normally waiting for the school summer holidays to go. Therefore, there were not a lot of people during the non-vocational months. This was compared to American parents, who would take their children out of school to go on holidays. The Europeans are reluctant to take their children from school for a vacation in mid-session whereas Americans do it frequently. Also, The Walt Disney Company was convinced that it would be able to "Americanize" the European habits. Unfortunately for the Walt Disney Company, this was not the case.

While attendance was strong when the park first opened, Euro Disneyland involved the computer stations at the hotels. Euro Disneyland executives assumed guests would stay at the park for several days. This in fact did not happen. Many guests arrived early in the morning, spent the day at the park, checked into the hotel late that night, and then checked out early the next morning before heading back to the park. In comparison to the United States, the average stay was four nights. They felt that this was because in Florida and California, there are multiple theme parks, not just one as in France. Since there were so many guests' checking-in and checking-out, additional computer stations had to be installed at the hotels in order to decrease the amount of time the guests stood in line.

Finally, in the initial design of the project, it was assumed that Europeans would be like Americans in term of transportation around the park and form the hotels to the park attractions. In the United States, a variety of trains, boats, and tramways carried visitors from hotel to the park. Although it was possible to walk, most Americans choose to ride. Europeans on the other hand choose to walk rather than ride, leaving the vehicles significantly underutilized. While not directly affecting revenues, the capital as well as ongoing costs for this transportation was considerable. Parking facilities were built accordingly as were facilities for bus drivers who would transport passengers to the park. Once again, the initial planning vastly underestimated the proportion of visitors who would arrive by bus as part of school, community or other group. Facilities for the bus drivers to park their buses and rest were inadequate. The problem initial solved.

\subsection{Financing and the initial business plan}

Euro Disney's key financial plan was that they would tightly control the design and build almost everything itself and 
then sell the completed properties at a large profit. In reality, it was found that there was little room for error that depended on the office parks and hotels surrounding the park to pay off, instead of the actual park.

The Walt Disney Company wanted to build a state of the art, as near to perfect as possible, theme park. In order to meet this goal the company frequently attempted to build and rebuild, with no regard for the "bottom-line" construction cost. Michael Eisner, the Chief Executive Officer of the Walt Disney Company, ordered several last-minute construction changes, known as budget-breakers, which further increased Euro Disneyland's debt. For example, one cold day before Euro Disneyland opened Eisner warmed himself by a Paris hotel lobby fireplace and ordered more than a dozen wood-burning fireplaces for Euro Disneyland despite the added construction cost and upkeep. Another example of an Eisner budget-breaker was his decision to remove two steel staircases from Euro Disneyland's Discoveryland. He wanted them removed because they blocked a view of the Star Tours ride. It was estimated the cost to remove the staircases was approximately $\$ 300,000$.

European investors also did not understand the concept of high-flying free markets and why shares were sold to individual investors with little tolerance for risk. There was also a European recession, resulting in unsuccessful business for Euro Disney.

Euro Disneyland executives and advisors failed to see the signs of the approaching European recession. "Between the glamour and the pressure of opening and the intensity of the project itself, we (the executives) didn't realize a major recession was coming". As the recession began to develop the French real-estate market tumbled (discussed below), thus, destroying Euro Disneyland's hopes of selling their assets and receiving revenues. In addition, the recession caused French and European disposable incomes to shrink, causing families to think twice about taking an expensive trip to Euro Disneyland .

Furthermore, Euro Disneyland did not realize the magnitude of the impending recession and when given numerous opportunities to sign partners who would share the risk or buy the existing hotels, Disney refused. Euro Disneyland did not want to give up any of the potential revenues once the recession was over.

Thicket prices for Euro Disney are also a problem considering that Disney want to attract not only locals but also tourists. Purchasing Power Parity comes in question when it comes to local currencies. Different currency values were not considered in the planning. European countries have different money currencies such as Germany's Deutsche Mark, France's Franc, Austria's Schilling and so on. At the end it was cheaper for the European tourists to travel to Florida and Orlando to visit one of the Disney Land Parks. Disney did not consider that European countries have different standards of living compared to American where they can afford to pay $\$ 30$ daily to visit Disney. Europeans cannot afford to pay 40 French Franks for a daily entry; this is due to difference of purchasing power parity of different visitors from all around the world.

\subsection{French labor laws}

Working abroad represents a significant change for any American company and Euro Disneyland did encounter problems with European laws and procedures. Employees balked at the company's dress code, and called in French labor inspectors. A ruling is awaited. Also, a dispute arose between French construction subcontractors and Disney overpayments. The company reached an arbitrated settlement with 40 subcontractors, but some disputes may go to court.

The French felt that the American management demoralized the work force, which also cut down the number of French visitors. According to a European labor economist, Disney did not understand the differences in the United States versus European Labor Laws. That meant that because there was cyclically in the attendance, American workers were scheduled to work, based on the day of the week and the time of the year. However, French labor laws did not provide this flexibility and could not operate at Euro Disney. Labor costs were significantly higher than in the United States.

Before the opening of Euro Disneyland executives had estimated labor cost would be $13 \%$ of their revenues. This was another area where the executives were wrong in their assumptions. In 1992 the true figure was $24 \%$ and in 1993 it increased to a whopping $40 \%$. These labor cost percentages increased Euro Disneyland's debt.

\subsection{Management hubris}

Disney also modified the theme park, so that it had attractions based on Frenchman Jules Verne's science fiction and a theatre with a 360-degree screen that featured European history. However, it still maintained American features such as Frontierland and Michael Jackson's Captain EO Movie. It adapted to the languages, making English and French the main languages, however, providing translators for the Dutch, Germans, Italians and Spanish.

Nevertheless, Euro Disney was wrong to assume that Europeans wanted American things; however, they failed to consider that the French "flatter themselves that they are more resistant to American cultural imperialism". Europeans felt that the American management system was bold and insensitive and that Americans were over-ambitious. Because of this, Euro Disney became known as "Cultural Chernobyl", creating hostility from the French people. 


\section{Recommendation}

We would recommend that Euro Disney restructure the way it operates on a number of levels. Unfortunately, it is impossible to relocate Euro Disney to the west of Paris, however, perhaps Euro Disney could initiate a promotion such as the Queensland theme parks do for its residence, which is offer a yearly pass for a very low cost. This may allow people who reside near the theme park to make trips to Euro Disney a frequent outing.

There had seemed to be a problem with the misunderstanding of the European lifestyles compared to the American lifestyle. Everything was built and set in a way, which was assumed that the European people's lifestyle was no different to the American lifestyle.

The colder months may have to be dealt with by also initiating better promotions to visit Euro Disney, as attendance at Euro Disney was seasonal. Perhaps discount family passes may be issued during the school year, so parents did not have to wait for the school summer holidays. If this did not work, Euro Disney could only for open fewer hours during the colder months.

More seating could be implemented so it could meet the demand for eating at the park, however because the park had high priced fast food, Euro Disney could cut down on the variety (as it is not appreciated anyway) of fast foods and introduce quality meals for a similar price. In reality, labor-saving magnetic cards replaced meal vouchers and the number of food items offered was reduced from 5400 to 2000 .

The revenues of food were significantly lower in Euro Disney then compared to the Disney parks. It was to be believed that Europeans did not eat big breakfast, and because of this, restaurants were planned to seat only a small number of breakfast guests. This was however found to be incorrect and was then rectified only after it was discovered. In fact, they were "...trying to serve 2,500 breakfasts in a 350-seat restaurant at some of the hotels". Further, guests wanted bacon and eggs rather than just coffee and croissants. Disney reacted quickly with prepackaged breakfasts delivered to rooms and satellite locations.

Usually Disney do not sell any alcohol within the park simply because for the keeping of the family-oriented values, while Euro Disney would need to recognize that alcohol is viewed as a regular beverage with meals and a part of daily European life, so maybe by introducing wine with meals will still let Europeans enjoy their beverages.

We should get to know and understand the European lifestyle and get to know what are the things Europeans normally like to do and what they may not like to do. We believe that by doing this it would save heaps of money for the company instead of wasting money rectifying problems after problems by assuming or misunderstanding the lifestyle of the Europeans to the Americans. Not all countries in the world live and have the same lifestyles, this is why we must study the lifestyles of how the people live so that when people come to visit the park there will not be any problems of coming out with money to rectify problem of not having enough seating place in restaurants, and etc.

As Europeans were also less attracted to buying souvenirs, they should cut down on production of souvenirs, which would cut some costs. In reality stores reduced merchandise from 30000 to 17000 . Because Europeans choose to walk, leaving vehicles under-utilized and therefore a waste of money, perhaps some of these vehicles should be sold. It would also be beneficial if the car park were adjusted to suit buses that brought in tour groups.

It was essential to raise funds to eliminate this debt. In order for Euro Disney to make these modifications, Disney may have to organize finance for the park from banks and form Walt Disney. In reality, fortunately, the creditor banks forgave eighteen months of interest payments and postponed payments for three years. They also allowed existing shareholders to purchase new shares at below market prices.

Because Euro Disney was wrong to assume that Europeans wanted American things, they failed to consider that the French people felt that the "uncontrollable problems were exacerbated by the arrogant attitude and cultural naivete of the American management". Euro Disney could solve this problem by promoting Europeans to the top management levels. It again in reality happened as Phillipe Bourguignon replaced Robert Fitzpatrick.

For the French labour issues, we must learn and understand the differences between U.S. versus European labour laws. Since the French workers are not scheduled based on the day of the week and time of year, may be then there should be a consideration of having to follow the European labour laws, after all the park is built in European country. We cannot simply use U.S labour laws in another country because the country itself has its own labour laws and not labour laws follow the same system. This way if we just follow the European labour laws, the only problem, which then needs work to be done on, is to find a way to come up with a solution on how we could lower the cost of labour in Euro Disney. Maybe we could be able to try training the workers to follow a schedule on the day of the week and the time of year basis.

A final proposition that was implemented was the changing of the name. Euro Disney was changed to Paris Disneyland, which indicated that there was a new beginning for this theme park. 


\section{Lessons from Disney' problem}

From observing the problems that Euro Disney had in relation to its theme park, we can observe that it is essential to study and accept the differing values of different nations. Marketers need to undertake extensive planning to avoid situations that may result in conflict or misunderstandings. We learn from this case that listening to the values and opinions of the people who live there would be beneficial to avoid problems relating to location, the environment and management strategies.

Cultural differences need to be addressed and not just assume that the foreign country will adopt domestic views. They way Europeans took holidays, bought souvenirs, took transport and ate, all affected Euro Disney's performance as what was implemented was wrongly assumed and therefore resulted in bad turn outs, because Europeans would rather continue doing what they were used to.

Facing also needed to be considered more carefully to avoid mis-spending on the wrong items (such as store merchandise and vehicles) instead of the items best suited to that area (alcohol and better quality meals).

We learnt that despite Disney adopting some European attractions at Euro Disney, they were wrong to assume that Europeans wanted American things, resulting in the Europeans feeling that the American management system was bold and insensitive. Therefore, it is essential to be sensitive and considerate of the Europeans needs.

Laws also need to be complied with, as Disney did not understand the differences in the United States compared to European Labor Laws. This resulted in a waste of funding because labor costs in Europe were significantly higher than in the United States.

Another thing that we have seen is that Europeans felt that the real experience of traveling to the United States where there was warmer and more attractions would be a better idea. This was also achievable because their currency bought more. This shows us that perhaps Europeans would have preferred to see the "real" American Disneyland, compared to a modified, smaller version, which was brought to them.

\section{Conclusion}

The lessons learned and experiences gained can apply to any country on the globe. For example, the Walt Disney Company failed to properly understand the eating habits of the Europeans. The lesson learned is that any meal providing company-contemplating expansion into any foreign market should be intensely indoctrinated on all aspects of the eating habits of people in and near that country.

In conclusion, it is evident to see that when embarking on an international endeavor. A move by any company to any foreign market should not be made without an extensive, in-depth study based on exhaustive research into every applicable aspect of new-home country. This includes the economy, laws, culture, climate, interests, customs, life-style habits, and geography, work habits, just to name a few. The list could go on and on with one area leading to another. Evidently, it is also important that these differences are not just assumed but true.

In order to determine the best way for a business to enter a new foreign market it should review past business experiences, which have settled in that particular market. Through these past experiences the business contemplating entering the market would have the ability to increase its chances of success as well as decrease its chances of failure.

\section{References}

Disney Record Loss on Charge for Euro Park. (1993). Wall Street Journal, 11.

Keegan, W.J. (2002). Global Marketing Management $7^{\text {th }}$ Ed. Prentice Hall, New Jersey. 